\title{
Estética e ética em Kierkegaard: inferências para a cultura pedagógica do Sudeste Goiano
}

\author{
Sérgio Pereira da Silva
}

Universidade Federal de Goiás

\begin{abstract}
Resumo
$\mathrm{O}$ presente artigo busca analisar a cultura pedagógica do $\mathrm{Su}-$ deste Goiano, mais especificamente alguns impasses educacionais que se manifestam no ensino básico e na formação de profissionais da educação na universidade. Temos como referencial teórico, principalmente, as reflexões sobre a ética e a estética, em Søren Kierkegaard, e os estudos sobre a cultura brasileira nas obras de Mario Vieira de Mello e de Regis de Morais. Em função de tais referenciais e de suas análises, esses impasses educacionais são caracterizados, neste artigo, como manifestações do estetismo na educação. Inicialmente, descrevemos as intuições de Kierkegaard sobre os modos de existência estético e ético e as confrontamos com os dados de algumas pesquisas que coordenamos desde 2003. As culturas de formação da região do Sudeste Goiano são o mote dessas pesquisas, tanto na formação dos profissionais do ensino, como na atuação destes em sala de aula. Concluímos que tem havido grande influência do estetismo na cultura educacional dessa região e apontamos estratégias pedagógicas, culturais e políticas de superação. Sendo um fenômeno cultural, podemos inferir que ele não se limita aos professores e às ações dos alunos, nem somente à esfera das práticas de ensino. Ele está presente na cultura universitária, na educação básica e nos espaços de gestão desses diferentes níveis de ensino, bem como nas políticas públicas para a educação.
\end{abstract}

\section{Palavras-chave}

Cultura pedagógica - Ética - Estética - Estetismo. 


\title{
Aesthetics and ethics in Kierkegaard: inferences for the pedagogical culture of Southeast Goiás
}

Sérgio Pereira da Silva

Federal University of Goiás

\begin{abstract}
The article seeks to analyze the pedagogical culture of Southeast Goias, more specifically some of the educational impasses that have been manifested in basic education and in the formation of education professionals at the university. Our theoretical framework is largely based on Søren Kierkegaard's reflections on ethics and aesthetics, and on the studies about the Brazilian culture found in the works of Mario Vieira de Mello and of Regis de Morais. In view of these references and their analyses, these educational impasses are characterized in this article as manifestations of aestheticism in education. Initially, we describe Kierkegaard's intuitions about the esthetic and ethic modes of existence, and we confront them with data from studies we coordinated since 2003. The formation cultures in Southeast Goiás are the focus of these studies, both regarding the formation of education professionals and their action in the classroom. We concluded that that has been strong influence from aestheticism in the education culture of this region, and we point towards pedagogical, cultural, and political strategies for overcoming it. Given that it is a cultural phenomenon, we can infer that it is not restricted to the teachers and to students' actions, nor is it limited to the sphere of teaching practices. It is present in the university culture, in basic education, and in the management spaces of these different levels of teaching, as well as in the public policies for education.
\end{abstract}

\section{Keywords}

Pedagogical culture - Ethics - Aesthetics - Aestheticism.

Contact:

Sérgio Pereira da Silva

Av. Max Margon, 283

75711-010 - Catalão/GO

E-mail: spsilva2010@gmail.com 
Aparecer ou ser - eis a questão! Essa exclamação é ilustrativa do dilema ocidental que tem a idade da filosofia. É verdadeiro aquilo que vemos, ou aquilo que intuímos racionalmente? Estamos, deveras, condenados à clausura de uma caverna onde, de costas para os objetos reais, imóveis, satisfazemo-nos com sombras projetadas pelo fogo na parede dessa caverna? Deleitamo-nos com a aparência copiada ou projetada pela luz que emana desse fogo? $\mathrm{Ou}$, por outro lado, podemos acessar uma verdade invisível aos olhos, podemos contemplar uma essência perene que nos proteja, moralmente, das cambiantes vicissitudes da existência humana?

Não somente na alegoria da caverna, mas em toda a metafísica socrático-platônica, sobretudo na polêmica entre o mundo das ideias, perene, essencial, não contraditório, e o mundo sensivel, aparente, transitório, superficial, encontramos o começo desse debate filosófico no Ocidente.

Em Fédon, na belíssima narrativa platônica dos momentos que antecedem a morte de Sócrates, o antagonismo entre ser e aparecer adquire importância fundamental. Em nenhuma outra reflexão desse filósofo ateniense encontramos uma ilustração tão apropositada da metafísica ( $\mu \varepsilon \tau \alpha$ Фvбıৎ - aquilo que é além do físico, além da matéria). Nesse diálogo, ao caracterizar a dor, o prazer, a morte como libertação do pensamento, ao definir a função da filosofia como o exercício racional que possibilita ao homem libertar-se das correntes que o mantêm cativo na ignorância, ser e aparecer revelam-se um dilema humano par excellence e mostram-se como dualismo fundamental dessa metafísica.

Entretanto, esses dois verbos não são sinônimos, nunca foram. A metafísica socrática e, posteriormente, a cristã conferem ao primeiro (ser) um valor de destaque em referência ao segundo (aparecer). Nessa perspectiva, aquilo que é, que não sofre a ação do tempo, que não se transforma, que não possui contradição etc., é necessariamente mais verdadeiro que aquilo que está, ou aquilo que aparece, que devém.

Tal polêmica ressurge no conflito entre racionalismo e empirismo, na aurora da modernidade. Porém, no início dos tempos modernos, essa filosofia essencial, cristianizada há aproximadamente 15 séculos, sofre contundentes críticas, dentre as quais enfatizamos o debate (que intenciona produzir um estatuto epistemológico) entre uma verdade intuída pela razão humana e uma verdade descoberta pela experiência.

Também em Friedrich Nietzsche, filósofo alemão do século XIX, a oposição entre uma verdade aparente e uma verdade racional recupera aquele dualismo, mas, dessa vez, contrapondo a cultura trágica à cultura racional metafísica. Aqueles valores conferidos pela metafísica são invertidos pelo filósofo de Röcken: é mais crível aquilo que se revela na aparência e mais enganosa a verdade racional. Em outras palavras, para Nietzsche, os fenômenos aparentes (os superficiais) têm um valor inédito e positivo, em contraposição aos fenômenos ocultos, essenciais (profundos), os quais, impregnados pela lógica, são desprezados por ele.

Porém, em Søren Kierkegaard, encontramos uma interessante reflexão sobre ética e estética que trouxe uma nova luz para os dilemas que enfrentamos e debatemos na formação de profissionais para o ensino, no Sudeste Goiano. Trata-se da descrição dos três modos de existência (estético, ético e religioso). Esses estádios são constructos didáticos e propedêuticos dos quais o filósofo dinamarquês se utilizou para mostrar as diferenças entre modos de vida, caracterizar os deslizes e polemizar em favor de uma moralidade menos pueril. Não são modelos generalizantes que negam a força das singularidades dos indivíduos, o que a estrutura didática de nossa organização textual pode, contra nossa intenção, sugerir.

Vamos ater-nos aos dois primeiros estádios para pensarmos, conforme nossas pesquisas indicam, o apreço conquistado pelo modo 
de existência estético na cultura do Sudeste Goiano, principalmente nas práticas e concepções pedagógicas.

Nossa reflexão, neste breve texto, retoma a discussão sobre o estetismo no Brasil, a partir da qual nos remeteremos ao estetismo ${ }^{1}$ na cultura pedagógica e no currículo de nossa região. Entendemos ser importante esclarecer que essa temática foi originalmente referência para Mario Vieira Mello em sua compreensão da gênese e do desenvolvimento da cultura brasileira, no livro intitulado Desenvolvimento e cultura: o problema do estetismo no Brasil, publicado em 1963. Por razões de hegemonia de outra perspectiva ideológica que dominava os círculos intelectuais e acadêmicos na época, inclusive na antropologia e na pedagogia, as discussões sobre o estetismo e sua instigante pertinência ética foram suprimidas, sob a acusação de serem um moralismo reacionário.

No prefácio da segunda edição, o autor lamenta ter sido acusado de moralista e se justifica afırmando tratar-se de uma injustiça e de um equívoco da crítica brasileira, que não compreendeu a relação que ele estabeleceu entre ética e estética. Comenta Mello (1980):

\begin{abstract}
Vários comentadores sugeriram [...] que eu atribuía uma posição privilegiada ao princípio ético. [...] embora eu tenha recorrido aos testemunhos de um Nietzsche, de um Kierkegaard, de um Dostoiévski, a crítica brasileira se sente manifestamente propensa a ver em mim o defensor do princípio ético - o que é sem a menor dúvida uma maneira delicada de presentear-me com o rótulo de moralista. (p. 16)
\end{abstract}

Uma estratégia, consciente ou não, de alguns apologistas de quaisquer ideologias ou tendências, no sentido de desmerecer uma reflexão ética original, tem sido estereotipá-la

1- São diversos os termos relativos ao estetismo como exacerbação da vida estética. Utilizaremos estetismo/esteticismo (cf. MELLO, 1963; MORAIS, 1989) e modo de existência estético (cf. GARDINER, 2001). como uma reflexão moralista e reacionária. Mello certamente foi vítima desse tentame.

Em 1989, no livro intitulado Cultura brasileira e educação (capítulos VI e VII), Regis de Morais discute as noções de aculturação, etnocentrismo e identidade cultural. A partir desses conceitos, ele analisa o processo de $\mathrm{eu}$ ropeização imperialista do mundo e as fases do europeísmo no Brasil, e, sensibilizado pelas análises de Mello, resgata a temática do estetismo na cultura brasileira e na educação, culminando com o estetismo no ensino universitário.

As iniciativas desses dois autores foram ousadas em tempos em que, no debate pedagógico, foram tão comuns os discursos de consenso, via de regra ideológicos, que espreitam o rótulo do politicamente correto e limitam-se a ele. 0 discurso de consenso ao qual nos referimos compreende que a cultura e, mais especificamente, a moralidade são necessariamente partes da superestrutura determinada pelas contradições do modo de produção.

Ora, os enfoques originais e não deterministas de Mello e de Morais colocaram-nos na contramão desse consenso e, sobretudo no caso do primeiro, vaticinaram seu ostracismo acadêmico. Entretanto, tais artimanhas políticas, restritas ao debate das ideias e inexpressivas que foram ante os demais processos de todo o tecido social, não mudaram os rumos estetizantes da constituição da cultura pedagógica do Sudeste Goiano, afirmação evidenciada por nossas pesquisas. Desse modo, o estetismo continuou fazendo história entre nós, não somente porque foram silenciadas as vozes que o denunciavam, mas, sobretudo, porque deixada livre para se propagar, essa cultura do aparente encontrou, em uma nação sem bases éticas consistentes e em tempos de capitalismo consumista, terreno fértil onde criou raízes e fez/faz história. Voltaremos a essa polêmica em outra oportunidade.

Neste texto, faremos uma breve descrição metodológica indicando as pesquisas que evidenciaram nossa problemática; em segui- 
da, analisaremos o conceito de estetismo e sua manifestação na universidade e na educação básica do Sudeste Goiano. Nossa problemática limita-se às inferências do estetismo para a cultura pedagógica do Sudeste Goiano; portanto, apesar de Kierkegaard ter descrito três modos de existência - o estético, o ético e o religioso -, iremos, para efeito de compreensão do estetismo, ater-nos apenas aos dois primeiros.

\section{As pesquisas}

São quatro pesquisas de campo, dentre as quais duas estão em andamento; suas respectivas leituras apontam para um pensar e um fazer pedagógico criticamente incipientes e estetizantes na cultura pedagógica do Sudeste Goiano. Entretanto, em nenhuma delas, sua original problemática incluiu, a priori, a investigação sobre estética ou ética nas práticas e no pensamento pedagógico do Sudeste Goiano. Tais perspectivas foram-se constituindo ao longo destes últimos anos.

A primeira (2003) foi intitulada "Treze anos de formação de profissionais do ensino, no Curso de Pedagogia (Universidade Federal de Goiás, Campus Catalão): avanços, limites e possibilidades para a cultura pedagógica regional”. Dentre várias constatações, foi reiterado o mérito do referido curso, na região do Sudeste Goiano, como responsável por extirpar da cultura pedagógica local a figura do professor leigo no ensino fundamental. Foram percebidas, ainda, limitações na formação desses profissionais, notadamente o baixo nível cultural e técnico para lidar com as tarefas cotidianas confiadas ao profissional pedagogo, e o alto índice de aprovação, a despeito dos resultados deficitários e do baixo interesse dos formandos.

A segunda (2004-2006) - "Crescente demanda pela pedagogia do saber-fazer no cotidiano das práticas de ensino escolar do Sudeste Goiano: exaustão da pedagogia ético-política?" - evidenciou uma procura por profissionais com domínio de turma, aptos para um saber-fazer imediatista, e revelou uma grande resistência ao que foi denominado formação exclusivamente teórica do pedagogo, com ênfase no discurso político.

A terceira, iniciada em 2006 e ainda em andamento no ano de 2009 - "Pedagogias do ressentimento ou da autonomia? Um olhar nietzschiano sobre o pensamento pedagógico brasileiro do século XX" -, introduziu o diferencial de ser uma pesquisa de campo respaldada pelo referencial teórico nietzschiano. Estamos investigando se, nessa região, as limitações na formação dos profissionais e a crescente demanda por uma pedagogia pragmática, portadora de excelência técnica, são tão somente respostas ao mercado ou podem ter resquícios de fenômenos/elementos culturais como o que Nietzsche chamou de ressentimento.

A quarta pesquisa, também em andamento (2009), é implementada em nosso estágio de pós-doutorado da Faculdade de Educação da UFU (2009-2010). Intitulada "Paideia, Didaqué/ Ratio Studiorum e Bildung: a formação humana sob suspeita”, busca responder à seguinte problemática: quais concepções e fundamentos filosóficos sustentam essas duas culturas formativas (para a excelência e para a redenção social) que hipoteticamente ditam os rumos do currículo das licenciaturas, dos bacharelados e dos cursos exatos (engenharias, bio-médicas e computação) na UFG, Campus Catalão?

Nessa quarta pesquisa, a preocupação com a formação de profissionais do ensino extrapola a pedagogia. Foram realizadas entrevistas com professores do ensino superior das licenciaturas, dos bacharelados e dos cursos exatos da UFG; as coordenadoras e as diretoras de escolas do ensino básico de Catalão, Ipameri, Goiandira, Nova Aurora e Cumari serão entrevistadas a partir de março de 2011. Ainda, serão analisados os projetos político-pedagógicos, os projetos de disciplinas e de cursos, e confrontados com os relatos das entrevistas. Implementaremos o mesmo procedimento na Universidade Federal de Goiás, Campus Catalão; no Centro 
de Ensino Superior de Catalão; na Universidade Católica de Goiás, Campus Ipameri; e na Universidade Estadual de Goiás, Campus Ipameri.

Quando das leituras dos clássicos do filósofo de Röcken e de alguns biógrafos e comentadores com vistas à terceira pesquisa, tivemos nosso primeiro contato com as obras de Mello, mais especificamente Nietzsche: o Sócrates de nossos tempos (1993), a partir da qual se foi descortinando um novo rumo para a pesquisa: os estudos culturais - dentre os quais, o debate sobre o estetismo - muito nos entusiasmaram. Aliás, durante a implementação das três primeiras pesquisas, o estetismo não fazia parte das temáticas que compunham nossas hipóteses iniciais; não conhecíamos ainda as obras de Mello e de Morais, que nos sensibilizaram com o enfoque culturalista e fizeram-nos revisitar a filosofia de Kierkegaard ${ }^{2}$. Porém, percebemos quando pesquisamos o Curso de Pedagogia e o pensamento pedagógico de nossa região - que as problemáticas evidenciadas nas três primeiras pesquisas concluem e confluem em favor de um ethos pedagógico com propriedades que caracterizamos, posteriormente, como estetizantes.

\section{O modo de existência estético}

Kierkegaard descreveu três modos de existência: estético, ético e religioso. Ao longo de sua obra, há, a nosso entender, uma nítida caracterização estruturalista desses modos de existência. Um tem o outro como referência, como etapa para ser superada, muito embora cada etapa guarde sua singularidade. Se o que interessa é a superação do estádio anterior, são etapas propedêuticas nas quais as diferenças de determinados modos de vida podem ser notadas. A moralidade que interessa ao filósofo extrapola os primeiros estádios, mas os pressupõe.

0 modo de existência estético é, dentre inúmeras características, descontínuo. Exemplificando: orientado pelo estetismo, o indivíduo

2- KIERKEGAARD, 1959, 1979a, 1979b, 2002; JOLIVET, 1950; FARAGO, 2005; GIMENES DE PAULA, 2001; GARDINER, 2001. inicia tarefas que não conclui; há, na origem da intuição dessas tarefas, ou mesmo no início de suas implementações, espetaculosos e retóricos empenhos de excelência, ao cabo dos quais acontece um esmorecimento da vontade. Desse modo, a implementação das tarefas não é concluída ou, na melhor hipótese, a conclusão é apressada e simplificada. Aliás, por supervalorizar o aparente e a ornamentação, o discurso inicial, para o indivíduo estético, basta por si só, porque os empenhos de implementação são exauridos na catarse de sua apresentação. Isso confirma a máxima de que a beleza inicial dispensa algo para além de si mesma. Esse algo seria a realização ou efetivação do projeto.

Daí a descontinuidade, a não conclusão. Há nesse modo de existência, conforme dissemos, uma nítida satisfação com a superficialidade e uma resistência aos discursos ou às práticas que exijam aprofundamentos, reflexões, conhecimento da mecânica oculta do aparecer e do ser. Em suma, não há conexão e relação entre teoria e prática: destas, a primeira adquire vida própria, emancipa-se; a segunda degenera-se em um fazer alienado e inconcluso. Ora, em sendo um fenômeno cultural, o indivíduo, nesse estetismo, não age dessa maneira propositalmente.

0 modo de existência estético é ilustrativo de uma consciência de si insegura, incompleta, incapaz (com baixa autoestima e confiança) e que necessita pegar emprestado de outra consciência (com características opostas, ou seja, com elevada autoestima e confiança) a imagem que deseja para si. A ausência de confiança e estima suficientes é consequente da percepção, ainda que não consciente, da inconsistência desse modo de existência.

Em Estética y ética en la formación de la personalidad, no início do segundo capítulo, Kierkegaard (1959) conceitua esses dois modos de existência:

Que é a estética em um homem, e o que é a ética nele? A essas questões responderei: a estética em um homem é aquilo pelo 
qual esse homem é, imediatamente; a ética é aquilo pelo qual ele se torna o que se torna. 0 que vive na estética, pela estética, da estética e para a estética que há nele, vive esteticamente. $^{3}$ (p. 35, tradução nossa)

Nessa citação, o filósofo dinamarquês ilustra a distinção do caráter imediato e contingente do estetismo, em contraposição ao caráter processual (no sentido de intencionalidade) da ética. Além disso, o advérbio imediatamente mostra que o indivíduo estético vive em um instante e deste não consegue abstrair-se. Por ser um instante fugidio, precisa extrair dele o maior glamour possível. Essa instantaneidade confere ao seu saber uma estatura hermenêutica relativa e limitada - em outra palavra, superficial.

0 imediatismo e a instantaneidade definem, pois, os espectros da superficialidade e da ornamentação próprios desse indivíduo e de suas ações. Ora, se o fenômeno aparece nas ações e no pensamento do indivíduo, seguramente estará em sua cultura, com proporcional performance. Vale dizer que o estetismo no cidadão tem uma relação dialética com o estetismo na sociedade, de um modo geral. Seu ser estético legitima e estimula o ser estético de sua cultura e vice-versa.

0 caráter ornamental e superficial desse fenômeno forja um ethos produtivo que nos é bastante familiar: o fazer pelo fazer, que, de resto, é uma ação destituída de intencionalidade e de compromisso morais para com a competência, esta que é a intenção e a ação de fazer o melhor possível, de abrasar-se com algo bem feito, de empenhar-se, no nível do sentido, em fazer o possível, exaurindo suas possibilidades.

Ora, o critério do empenho, no nível do sentido, presente no parágrafo anterior, remete-nos ao conceito marxista de alienação: o fazer próprio daquele indivíduo que perdeu a intencionalidade

3- "¿Que es la estética en un hombre, y que es la ética en él? A resto responderé: la estética en un hombre es aquello por lo cual ese hombre es, inmediatamente, lo que es; la ética es aquello por lo cual deviene lo que deviene. El que vive en la estética, por la estética, de la estética y para la estética que hay en él, vive estéticamente." inerente a uma vida integrada à totalidade, na qual opção e ação têm objetivos conscientes, políticos e morais, compromissados com os interesses de classe.

Em Kierkegaard (1959), não vemos esse apelo de classe porque a superação do estetismo é uma conversão individual; porém, esse caráter individual não sugere o célebre e liberal individualismo burguês, pois se trata de uma superação particular relacionada a um projeto universal de sociedade. Afırma o filósofo:

Como individuo particular, não sou universal e não seria absurdo que me pedissem que o fosse; porém, se devo estar em condições de efetuar o universal [ações e concepções], devo ser universal e, ao mesmo tempo, particular. Desse modo, a dialética do dever se encontra em mim mesmo. ${ }^{4}$ (p. 148, tradução nossa)

Chama-nos atenção, no trecho citado, a ênfase do autor ao caráter relacional, e não excludente, desse modo de ser universal ou particular. 0 caráter relacional, ou dialético, caracteriza um empenho produtivo moral que, diferentemente do fazer pelo fazer, é uma ação individual compromissada com a cultura que, por seu turno, é uma referência maior fundamental para a constituição da alteridade particular.

Cientes da relação entre as dimensões individuais e coletivas, na constituição do dever e da moral, passamos à análise da gênese do estetismo no indivíduo.

Patrick Gardiner (2001), utilizando-se de uma análise psicológica e existencial do indivíduo e do grupo social, refere-se ao estetismo, também inspirado em Kierkegaard, afırmando que o indivíduo estético é desenraizado, descompromissado, e que seus empenhos não têm firmeza e propósito de continuidade. Para Gardiner (2001),

4- "Como individuo particular yo no soy lo general, y sería absurdo que me pidieran que lo fuera; por lo tanto, si debo estar en condiciones de efectuar lo general, debo ser lo general al mismo tiempo que lo particular y, entonces, la dialéctica del deber se encuentra en mí mismo." 
o indivíduo que vive esteticamente não está realmente no controle, seja no de si mesmo, seja no de sua situação. [...] Sem compromisso com nada permanente ou definido, disperso no "imediatismo" sensual, ele pode pensar ou agir de uma forma num momento e de outra mais tarde. Sua vida, portanto, não tem continuidade, falta-lhe estabilidade ou objetivo; ele muda de rumo conforme o humor ou as circunstâncias, "como uma carta mágica, da qual se pode depreender um sentido agora e outro depois, dependendo de como se olha para ela”. (p. 53)

Nessa caracterização do indivíduo estético, Gardiner concorda com a afirmação de Kierkegaard a respeito do caráter heterônomo, descompromissado, imediatista e disperso do estetismo. Ou seja, um indivíduo estetizado não tem o controle e as rédeas dos processos nos quais está inserido (daí termos utilizado, em algum dos parágrafos anteriores, a expressão ainda que não consciente); não tem comportamento coerente, e intencional, para com os objetivos e para com os alvos a serem atingidos.

Ora, essa ausência de controle de si mesmo dá-se em função do desespero: "toda concepção estética da vida é um estado de desespero" (KIERKEGAARD, 1959, p. 95). Porém, o filósofo dinamarquês tem uma leitura positiva desse estado de desespero por percebê-lo como salvação desse indivíduo: a consciência, ou inconsciência, da frivolidade do modo de existência estético, no indivíduo, leva-o ao desespero porque o leva a perceber a perda de si mesmo causada por um existir sensual, descompromissado, superficial etc.

Está implícita, na análise de Kierkegaard, a constatação de que os valores éticos estão, digamos, ocultos na cultura; que os lampejos de sua consciência de si fugidia revelam o vazio existencial no qual se resume sua vida. Daí o desespero e, a partir deste, o processo de superação do estetismo.
Ousamos, desse modo, uma dedução plausivel: a eticidade verdadeira pressupõe os porões errantes da vida estética porque, segundo Kierkegaard (1959),

ao falar da concepção estética da vida - ganhar o mundo inteiro e perder-se a si mesmo e à sua alma -, falo do desespero, porém estou convencido de que o desespero é para o homem a verdadeira salvação. Novamente, vemos que é importante querer o desespero, querê-lo em sentido infınito, em sentido absoluto, pois tal querer equivale ao esquecimento absoluto de si mesmo. Por outro lado, se quero o desespero, em sentido finito, perco minha alma porque, desse modo, minha natureza mais intima não se manifesta no desespero. ${ }^{5}$ (p. 90, tradução nossa)

Ou seja, um abandono infinito no desespero implica uma ousada espreita de si mesmo, um corajoso exercício de autoconhecimento e um despojamento dos prazeres estéticos em prol do conhecimento de si. É exatamente por não se conhecer, por não se valorizar e estimar que "esse estádio [estético] constitui um constante exercício de preencher um vazio existencial com elementos tomados de empréstimos, sob o pânico de aparecer aos próprios olhos e aos alheios como nada" (MORAIS, 2002, p. 126).

Desse modo, o indivíduo estético e sua alegria estrepitosa, sua sensualidade instantânea, seu descompromisso, sua irreverência etc, podem ser uma aparência que dissimula a autopercepção de sua fragilidade, de sua inconsistência e de sua descontinuidade. Ao perceber-se inautêntico, busca emprestado, nos indivíduos e nas culturas que admira, uma subjetividade e

\footnotetext{
5- "al hablar de la concepción estética de la vida, ganar el mundo entero perdiendo el alma es la desesperación y, sin embargo, estoy convencido de que la desesperación es para el hombre la verdadera salvación. De nuevo vemos que es importante querer su desesperación, quererla en sentido infinito, en sentido absoluto, pues tal querer equivale al olvido absoluto de sí mismo. En cambio, si quiero mi desesperación en sentido finito, pierdo mi alma, porque entonces mi naturaleza más íntima no se manifiesta en la desesperación."
} 
um modo de ser e de existir que passa a considerar seus. Assim surgem os modismos que copiam a estética e os modos de ser europeus, norte-americanos etc. Ou mesmo os modismos no interior do país, que copiam os modos de ser das grandes metrópoles brasileiras.

\section{O modo de existência estético no Brasil}

Ainda em Cultura brasileira e educação (2002), Morais, ao caracterizar o estetismo, enfatiza a superficialidade desse fenômeno cultural. Afirma que tal fenômeno revela um modo de existência que, por não ter raízes que profunda e virilmente poderiam adentrar os mananciais éticos da cultura europeia, foi uma das razões fundamentais para a constituição, no século XIX, de uma cultura brasileira inconsistente. Ou seja, uma cultura iniciante e titubeante nos seguintes quesitos: rigor, profundidade, continuidade, firmeza nos princípios, alteridade etc. 0 hábito de o indivíduo estético satisfazer-se com a ornamentação já nos dá indícios de que essa superficialidade cultural pode ser fruto de uma séria crise de identidade individual e coletiva. Comenta Morais (2002):

0 caráter estetizante tipifica a existência desenraizada e, por isso, furtiva, a que se aceita como acidente efêmero, sem a certeza de que vale a pena ter um projeto sólido e realizá-lo. Trata-se, por outro lado, de uma existência que percebe a realidade, mas uma realidade entre aspas, porque forjada por um conjunto de aparências. [...] 0 sentido do provisório e do improvisado, a dificuldade de identificar raízes próprias ou dotadas de autoctonismo, a quase impossibilidade que temos [brasileiros] enfrentado de desenvolver um projeto cultural próprio. [...] realmente uma vida cultural profundamente marcada por preocupações de aparência, construtora de belas fachadas por trás das quais agita-se séria crise de identidade consequente a uma história de submissões que vêm amordaçando nosso potencial criativo. (p. 126-127)
O final da citação já nos sugere que o amordaçamento da criatividade brasileira e a dificuldade de implementação de uma alteridade étnica advêm de nossa baixa autoestima cultural, da ausência de raizes profunda e secularmente fincadas em mananciais éticos. Estes, no contexto do projeto colonizador do tipo povoamento (e não de exploração lusitana, como foi o caso brasileiro), possibilitariam que superássemos o primeiro estágio. Apesar de a colônia ser necessária e culturalmente dependente e heterônoma, um projeto que visasse à sua emancipação poderia ter contribuído, talvez antes mesmo de nossa independência de Portugal, para o surgimento da tão especulada e sonhada alteridade cultural brasileira.

Uma formação cultural heterônoma e inconsistente, quando ainda colônia, tornou-nos (a nós, brasileiros) vulneráveis aos ventos estetizantes (românticos) do século XIX. Em termos kierkegaardianos e nas perspectivas de Mello e de Morais, faltaram-nos modelos e claras referências culturais moralizantes quando de nossa colonização, fato que nos manteve em estado de desespero. Por isso, conscientes ou inconscientes de nossas limitações culturais, importamos modismos, identidades e condutas dos ícones culturais. Além de importar modelos, passamos a venerá-los, comportamento típico do indivíduo e da cultura com baixa autoestima.

Essa veneração, a ornamentação, o jeitinho brasileiro, o imediatismo, a superficialidade e a percepção da ausência de raizes fincadas em milenares mananciais éticos etc., proporcionam um estado de melancolia, primeiro passo rumo ao desespero, que é a crise do estádio estético, crise necessária para sua superação. Sobre isso, afirma Kierkegaard (1959):

Na vida do homem, chega um momento em que o imediatismo, digamos, esgotou-se; em que o espírito aspira a uma forma superior, na qual deseja assumir-se como espírito. 0 homem, como espírito imediato, limita-se à vida terrestre. Quando o espírito concentra-se sobre si mesmo, quer sair dessa dispersão e 
consubstanciar-se em si mesmo; a personalidade quer tomar consciência de si mesma e de sua validez eterna. Se isso não acontece, [...] surge a melancolia. ${ }^{6}$ (p. 48, tradução nossa)

A melancolia, como primeiro sintoma de um desespero, é sintoma de uma passagem do modo de existência estético ao modo de existência ético. Esse sofrimento de alguém que percebe como sendo frívola a base de sua existência induz à mudança, produz inquietude, mal-estar, crise. Na perspectiva de Kierkegaard, o espírito humano, em estado de desespero existencial, aspira à profundidade, ao compromisso, à continuidade, à seriedade, ou seja, aspira ao estádio ético. no Brasil?

Como surgiu e se estruturou o estetismo

Mario Vieira de Mello (1986, 1980) aponta para a colonização lusitana, para sua cultura colonizadora de exploração e sua superficial compreensão e divulgação do Renascimento Italiano (entre os séculos XIV e XVI). Os portugueses teriam se apropriado do resgate italiano, da estética greco-clássica, via França e Espanha, sobretudo via Romantismo Francês do século XIX, cujo pai intelectual foi inegavelmente Jean-Jaques Rousseau. Para Mello, Rousseau teria sido uma frágil, inconsistente e romântica (aparência, ornamentação) apropriação daquele movimento cultural italiano e de seus recursos éticos. Rousseau, profundamente tocado pelas contradições sociais e morais de seu tempo, ateve-se à emoção e ao saudosismo naturais, que em nada lembram os renascentistas Da Vinci, Petrarca, Castiglione, Maquiavel, Botticelli, Michelangelo, Rafael, dentre outros, ou mesmo os guerreiros da lírica ou da tragédia descritos por Homero e por Sófocles, além de

6- "En la vida del hombre llega un momento en que la inmediatez, por decirlo así, ha madurado, en que el espiritu aspira a una forma superior en la que quiere apoderarse de sí mismo como espíritu. El hombre, en cuanto espiritu inmediato, es función de toda la vida terrestre y el espiritu, concentrándose sobre sí mismo, quiere salir de esa dispersión y transfigurarse en sí mismo; la personalidad quiere tomar conciencia de sí misma en su validez eterna. Si esto no sucede, [...] entonces aparece la melancolía." outros poetas e dramaturgos gregos. Segundo Mello, havia na França outras referências mais consistentes, menos sensuais, menos românticas..., mais realistas.

Os portugueses deveriam ter bebido nas originais fontes italianas, em que as genuínas intuições estéticas ressuscitaram o espírito trágico-grego (impregnado de valores éticos, compromisso, despojamento, coragem, honra, espírito de pertença ao grupo social etc.). A apropriação portuguesa do Renascimento Italiano sofreu as perdas e deturpações inerentes aos pensamentos que, transitando por diversos espaços hermenêuticos, adquiriram acréscimos e perderam elementos fundamentais. Desse modo, o estetismo que herdamos dos portugueses foi uma espécie de subproduto, copiado e mal acabado, do que originalmente foi o Renascimento Italiano.

Se as referências renascentistas lusitanas fossem diretamente os italianos, talvez os portugueses tivessem se fortalecido culturalmente e pudessem ter transmitido aos brasileiros, não fosse a exploração a única intenção colonizadora dos lusitanos, bases éticas consistentes para essa cultura emergente nos trópicos. Teria chegado até nós, desse modo, o verdadeiro espírito estético e não o reles estetismo que deturpou o legado da Grécia clássica.

Para Mello e Morais, nossos primeiros acadêmicos, em sua maioria juristas, com o peso moral de primeiros professores graduados em Portugal, foram responsáveis pelo ensino de diversas áreas, inclusive de filosofia, no Brasil. Ora, como Morais (2002) mostrou-nos, esses primeiros professores tinham um "gosto pelo espetaculoso que tem sido o timbre das escolas e grupos jurisconsultos no Brasil” (p. 132). Não é de se admirar, pois, que nossos primeiros docentes universitários, com seu brilho retórico, tenham trazido de Portugal os germes do estetismo no interior de suas boas intenções formativas. Para esses juristas, o belo antecedia, em valor moral, o verdadeiro; o empolgante, o idôneo; o brilho, a seriedade; a complacência, o rigor. 
Desse modo, nosso Brasil civilizado nasceu em um contexto imoral, habituado aos exemplos de pilhagem, superficialidade, descontinuidade e fragilidade dos projetos culturais, sociais e políticos. Nasceu sem raizes fincadas nos mananciais éticos forjados pelas grandes e seculares culturas europeias. De lá para cá, modismos e descontinuidades alternam-se, e, quando fala mais alto nosso importado estetismo, tendemos a ser, cada vez mais, espetaculosos, histriônicos e superficiais. Nosso empenho e nosso rigor, nessa oportunidade, têm fôlego curto porque o espetáculo de nossa retórica já nos satisfaz; nossa catarse, nosso show discursivo, em uma cultura estetizante, bastam por si só.

Especificamente no que tange às práticas de ensino e às, digamos, práticas de aprendizagem, atualmente (início do século XXI), acreditamos que a cultura educacional do Sudeste Goiano ainda é refém do estetismo, como veremos a seguir.

\section{O modo de existência estético na cultura pedagógica do Sudeste Goiano}

Para não incorrermos em um determinismo imperdoável, compreendemos como sendo importante salientar que nossa intenção de caracterizar o fenômeno educacional que pesquisamos como estetizante inscreve-se na lógica do perspectivismo ${ }^{7}$ nietzschiano. Ou seja, nossa perspectiva é mais um ponto de vista, mais um ponto de mirada de uma realidade que só será esculpida por muitas mãos, por muitas mentes e por muitos olhos. Oxalá as demais perspectivas tenham a mesma intenção de acolhimento, e composição, de uma atitude crítica

7- Perspectivismo, conforme Losurdo (2009), é um conceito epistemológico segundo 0 qual a percepção e o pensamento têm um lugar determinado. Originalmente intuído por Leibniz, o perspectivismo foi enfatizado e estruturado por Nietzsche, que o diferenciou de objetivismo e de relativismo. Crê-se que, como o objetivismo, há uma única realidade, porém cada pessoa a vê subjetivamente; crê-se, como o relativismo, na pluralidade de visões, entretanto, não se crê que tal pluralidade enseje diferentes realidades. e plural na compreensão desse fenômeno da cultura pedagógica do Sudeste Goiano.

Há, ainda, nossa preocupação em enfatizar a existência de incontáveis experiências educacionais que revelam a tentativa de superação do estetismo na cultura pedagógica do Sudeste Goiano. Se aqui enfatizamos esse traço cultural, fazemo-no propositalmente para que o leitor forje avanços no fazer e no pensar educacionais. Em outras palavras, se Kierkegaard confere aos modos de existência um caráter propedêutico, assim também o fazemos com nossa ênfase no estetismo das práticas e dos discursos pedagógicos dessa região, torcendo para que o debate continue, tendo-nos, tão somente, como referência ou pressuposto.

$\mathrm{Na}$ cultura escolar e acadêmica que pesquisamos, o estetismo não é um fenômeno encontrado exclusivamente nas práticas docentes ou discentes, exatamente pelo caráter relacional do processo cultural. Para cada ação do discente, há uma correlação estimulante nas práticas docentes e a conivência dos gestores da educação, em todos os níveis. Essa relação extrapola os espaços educativos institucionais e encontra legitimação e estímulo nas demais arenas sociais.

Há, desse modo, uma espécie de pacto tácito e dialético, no qual gestores, docentes e discentes - cidadãos, em geral - estimulam e legitimam o estetismo na cultura pedagógica do Sudeste Goiano, gerando um círculo vicioso. Portanto, não há culpados individualizados no ponto de chegada desse fenômeno. Não há uma consciente e maquiavélica intencionalidade que organize e programe essas posturas e atitudes.

E não falamos apenas a partir dos dados dessas pesquisas de campo. Vinte anos como docentes do ensino básico e superior, em Goiás, possibilitaram-nos inumeráveis oportunidades para vislumbrarmos os resquícios, ou a proeminência, do estetismo nas concepções pedagógicas, oportunidades essas posteriormente reiteradas pelas sistemáticas pesquisas já descritas. Selecionamos algumas ilustrações desse estetismo na cultura educacional: 
- currículo para inglês ver: espetaculosos eventos de lançamento de projetos político-pedagógicos que não suportaram uma semana de confronto com a realidade da cultura pedagógica local, mesmo porque não havia a intenção de continuidade possuidora de estratégias para tal confronto;

- eventos de capacitação de professores, os quais são mantidos sob coerção/controle da presença registrada e assinada, reforçando a ideia de que a presença é o bastante;

- incontáveis alunos e alunas que compreendem como suficiente aparecerem na sala de aula para apenas responderem às exigências burocráticas (o fazer-de-conta-que-se-faz), em vez de serem presença desejante e exemplo de vontade de saber e de conhecer; isso reitera a convicção de que o ritual pedagógico é suficiente por si só;

- tal convicção é legitimada por pais, professores, gestores e órgãos que criam e implementam as políticas educacionais etc.;

- grande empenho na aparência e na ornamentação (primeira capa) dos trabalhos escolares, nos projetos de curso e de pesquisa acadêmicos, e fragilidade, ou superficialidade, no conteúdo e na extensão dos mesmos;

- leitura superficial da bibliografia solicitada pelo professor (ensinos básico e superior), assim como ausência de aprofundamento teórico, devido à confiança (não aleatória) de que leitura e estudo não implementados serão perdoados;

- essa leitura superficial e demais tarefas cumpridas superficialmente são legitimadas pela falta de rigor na avaliação do docente e pela ausência de cobrança sistemática em relação ao cumprimento do que foi acordado ou exigido;

- excessivo empenho no debate e nas polêmicas políticas, em sala de aula, sem correspondente aprofundamento teórico da temática polemizada ou mesmo conhecimento de outras perspectivas; - formação docente no nível stricto sensu é cativa do discurso politicamente correto, em vez de desenvolver compromisso acadêmico com a criatividade, com a sensibilidade social e com a excelência na produção humanista e científica;
- carreirismo lattes, enfatizando a ornamentação quantitativa da produção em detrimento da qualidade;

- subserviência aos critérios acadêmicos e aos modelos formativos estrangeiros em detrimento das alteridades locais.

Por último, embora haja mais exemplos, sempre nos indignou a arrogância e a empáfıa muito comuns na militância sindical dos profissionais do ensino, especialistas na retórica e na articulação, mas resistentes à escuta, ao diálogo e às demais alternativas políticas. Nesse comportamento militante está implícita (talvez inconsciente) a convicção dogmática e estética de que o discurso bem articulado é suficiente e não necessita da mediação das pequenas e insignificantes contribuições ou implementações da vida material.

As constatações descritas acima, além de outras que já são de domínio público, não deixam dúvidas, em nosso entendimento, de que o estetismo atualmente impregna o currículo escolar (ensino básico) e a formação de profissionais para a escola (ensino superior) no Sudeste Goiano. Revelam que nossas metodologias de ensino, nossas práticas de estudo e de avaliação e, enfım, nossa conduta pedagógica têm fortes resquícios daquele fenômeno cultural que sufoca ímpetos de originalidade, destrói a autonomia e inviabiliza a excelência - em outros termos, fragiliza nossos empenhos de rigor e de justiça, assim como nossos valores mais caros.

\section{Considerações finais}

As reflexões de Morais e de Mello, bem como as intuições de Kierkegaard precisam, e intencionamos fazê-lo, de aprofundamentos que extrapolam os limites deste texto; tais reflexões, porém, induzem-nos a crer que o estetismo fragilizou nossos tímidos empenhos de seriedade, continuidade e profundidade nas mais diversas ações e reflexões que constituem nosso ethos educacional no Sudeste Goiano. Percebemos que esse impasse vai além da edu- 
cação formal e condiciona as diversas atividades no trabalho, na práxis política, na administração dos bens públicos, nos rituais e ações de cunho religioso, nas relações interpessoais etc. As exceções não são suficientes para conferirem um sentido ético à nossa cultura geral, ou mesmo à nossa cultura pedagógica, na referida região e em grande parte do país.

Entretanto, Morais e Mello não consideram nosso dilema pedagógico-cultural uma guerra perdida. Para exemplificar, Mello (1980) aponta uma, dentre tantas, possibilidade de superação do estetismo:

Se quiséssemos verdadeiramente realizar um
esforço de regeneração ética da nossa cultu-
ra, o caminho a seguir teria que ser forçosa-
mente outro. Uma tentativa sincera de com-
preensão do fenômeno do Estetismo deveria
constituir a primeira etapa desse trabalho de
recuperação. A compreensão desse fenôme-
no nos levaria a relacionar a idéia de Belo
à idéia do Bem, a ter em vista a modifica-
ção que o Renascimento italiano introduziu nessa relação e a relembrar o fato de que em outras eras as duas idéias viviam ao lado uma da outra e que não havia entre elas nem conflito nem desarmonia. (p. 256)

A regeneração proposta por Mello requer resgatar a relação entre ética e estética, entre o belo e o bem. Ou seja, o belo não basta por si só, precisamos forjar valores, intencionalidades (empenho) e, sobretudo, ações ilustrativas de uma nova cultura pedagógica com seriedade (sem jamais perder a ternura!), continuidade e profundidade pouco comuns em nossos meios educacionais.

$\mathrm{Na}$ escola e nas organizações gestoras (nas esferas municipal, estadual e federal), na família, na igreja, no sindicato, no espaço produtivo e nos meios de comunicação, tal regeneração é condição de possibilidade para que o círculo vicioso estetizante seja interrompido. Isso feito, uma revolução ética será adequadamente efetivada, na qual o bem e o belo resgatem o sentido da indissociabilidade que os constitui.

\section{Referências}

FARAGO, F. Compreender Kierkegaard. 2. ed. Petrópolis: Vozes, 2005.

GARDINER, P. Kierkegaard. São Paulo: Loyola, 2001.

GIMENES DE PAULA, M. Socratismo e cristianismo em Kierkegaard: o escândalo e a loucura. São Paulo: Annablume/Fapesp, 2001.

JOLIVET, R. Las doctrinas existencialistas. Madrid: Editorial Gredos, 1950.

KIERKEGAARD, S. Estética y ética en la formación de la personalidad. Buenos Aires: Editorial Nova, 1959. Temor e tremor. In: . Os pensadores, v. XXXI. São Paulo: Abril Cultural, 1979a. . 0 desespero humano. In: Os pensadores, v. XXXI. São Paulo: Abril Cultural, 1979b.

. Diário de um sedutor. São Paulo: Martin Claret, 2002. 
LOSURDO, D. Nietzsche: 0 rebelde aristocrata. Rio de Janeiro: Revan, 2009.

MELLO, M. V. Desenvolvimento e cultura: o problema do esteticismo no Brasil. 3. ed. Rio de Janeiro: Paz e Terra, 1980. . 0 conceito de uma educação da cultura. São Paulo: Paz e Terra, 1986. . Nietzsche: 0 Sócrates de nossos tempos. São Paulo: Edusp, 1993.

MORAIS, R. Cultura brasileira e educação. 1. ed. Campinas: Papirus, 1989. Cultura brasileira e educação. 2. ed. Campinas: Papirus, 2002.

Recebido em 26.03.10

Aprovado em 12.09.10

Sérgio Pereira da Silva é professor do Departamento de Pedagogia da Universidade Federal de Goiás, Campus Catalão. 